\title{
Coronary Revascularization and Out-of-hospital Cardiac Arrest: Past, Present and Future
}

\author{
Matthew E Li Kam Wa, 1,2 Kalpa De Silva, 1,2 Nilesh Pareek ${ }^{2,3}$ and Divaka Perera1,2 \\ 1. Cardiovascular Division, St Thomas' Hospital, Guy's and St Thomas' NHS Foundation Trust, London, UK; 2. British Heart Foundation Centre \\ of Excellence and National Institute for Health Research Biomedical Research Centre, King's College London, London, UK; 3. King's College \\ Hospital, King's College Hospital NHS Foundation Trust, London, UK
}

DOI: https://doi.org/10.17925/HI.2021.15.2.94

$\mathrm{C}$ ardiologists and the cardiac catheter laboratory have key roles to play in the management of patients after out-of-hospital cardiac arrest (OHCA). Although immediate catheter laboratory activation is the standard of care in cardiogenic shock and ST elevation myocardial infarction, the majority of patients will present without these features and with an uncertain diagnosis. Even in the latter, early assessment and invasive management may be beneficial, but this is counterbalanced by significant resource utilization, potential to cause harm and the possibility that any diagnostic or therapeutic gains are offset by a poor neurological outcome. Past consensus on the management of the OHCA patient without ST elevation or cardiogenic shock is being challenged by emerging results from new trials in this field. Further randomized trials are ongoing, and are expected to deliver robust data from over 4,000 patients, allowing us to further refine the optimal management strategy in this challenging cohort. This article describes the benefits and pitfalls of a strategy of immediate coronary angiography in these patients, examines the recently published COACT and TOMAHAWK trials in detail, and describes a framework with which to approach the patient after resuscitated OHCA, based on the available evidence to date.

\section{Keywords}

Out-of-hospital cardiac arrest, coronary angiography, non-ST elevation myocardial infarction, percutaneous coronary intervention, cardiac catheterization, real-world clinical trials

Disclosures: Matthew E Li Kam Wa, Kalpa De Silva, Nilesh Pareek and Divaka Perera are supported by grants from the British Heart Foundation (including CS/16/3/32615 for the ARREST trial and the Centre of Research Excellence Award, RE/18/2/34213), and the UK National Institute for Health Research through the Biomedical Research Centre award to King's College London and Guy's and St Thomas' Hospital.

Review process: Double-blind peer review.

Compliance with ethics: This study involves a review of the literature and did not involve any studies with human or animal subjects performed by any of the authors.

Data availability: Data sharing is not applicable to this article as no datasets were generated or analysed during the writing of this article.

Authorship: The named authors meet the Internationa Committee of Medical Journal Editors (ICMJE) criteria for authorship of this manuscript, take responsibility for the integrity of the work as a whole, and have given final approval for the version to be published. Access: This article is freely accessible at touchCARDIO.com. ( Touch Medical Media 2021

Received: 27 October 2021

Accepted: 24 November 2021

Published online: 20 December 2021

Citation: Heart International. 2021;15(2):94-102

Corresponding author: Matthew E Li Kam Wa,

Cardiovascular Division, Rayne Institute, St Thomas'

Hospital, London, SE1 7EH, UK. E: mlikamwa@nhs.net

Support: No funding was received in

the publication of this article.
The true epidemiology of out-of-hospital cardiac arrest (OHCA) is difficult to define, with wide variations in reporting, management and outcomes worldwide. ${ }^{1,2}$ In Europe, the incidence of OHCA is estimated to be between 67 and 170 per 100,000 people and it continues to be a major public health challenge that is reliant on multiple links in a 'chain of survival' to improve outcomes. ${ }^{3}$ For patients who survive and are admitted to hospital, ongoing management is based upon organ support and the diagnosis and treatment of an underlying cause. This article focuses on recent developments that are changing our understanding about the role of the cardiac catheter laboratory in the resuscitated OHCA patient without ST elevation or cardiogenic shock (the third pathway depicted in Figure 1). ${ }^{4-8}$

\section{The cardiac catheter laboratory}

Activation of the cardiac catheter laboratory and its associated multidisciplinary team can provide a multifaceted service to the OHCA patient, the majority of which will have a cardiac cause for their arrest. ${ }^{9}$ First, it provides immediate diagnostic evaluation by the interventional cardiology team. The alternative strategy, for the patient to be taken to the nearest hospital regardless of primary capability in percutaneous coronary intervention (PCl), could result in heterogeneity of care due to regional differences, particularly with non-specialist hospitals. Second, invasive procedures such as coronary angiography and right heart catheterization may inform diagnosis and ongoing patient care, even when $\mathrm{PCl}$ is not indicated. Third, it provides the option for placement of percutaneous mechanical support devices for those in cardiogenic shock (Figure 1).

These benefits do have fiscal implications, however, and can potentially increase the risk to the patient (Figure 2). Provision of a 24-hour cardiac catheter laboratory is resource intensive, and out of hours, it may utilize staff that are required to work the following day. Coronary angiography can lead to delays in neuroprotective measures or in the diagnosis and treatment of non-coronary causes for cardiac arrest. ${ }^{2}$ Although coronary disease (either atherosclerotic due to plaque disruption, or non-atherosclerotic, such as spontaneous coronary artery dissection) is the predominant aetiology for cardiac OHCA, other causes such as cardiomyopathy, valvular heart disease, congenital heart disease and primary electrical abnormalities must be considered. It also places patients at risk for: 1) procedural complications, such as bleeding due to the use of pharmacological adjuncts; 2) renal injury due to the administration of iodinated contrast to kidneys that have already suffered an ischaemic insult; ${ }^{10}$ and 3) potential neurological injury from contrast crossing a compromised blood-brain barrier, ${ }_{11}^{11}$ coupled with any haemodynamic instability that may be induced by PCI.

This risk-benefit ratio is shifted in favour of catheter laboratory activation, however, when the probability of identifying clinically relevant coronary artery disease is high. In two observational 
Figure 1: Catheter laboratory interventions after out-of-hospital cardiac arrest with guideline recommendations ${ }^{4-8}$

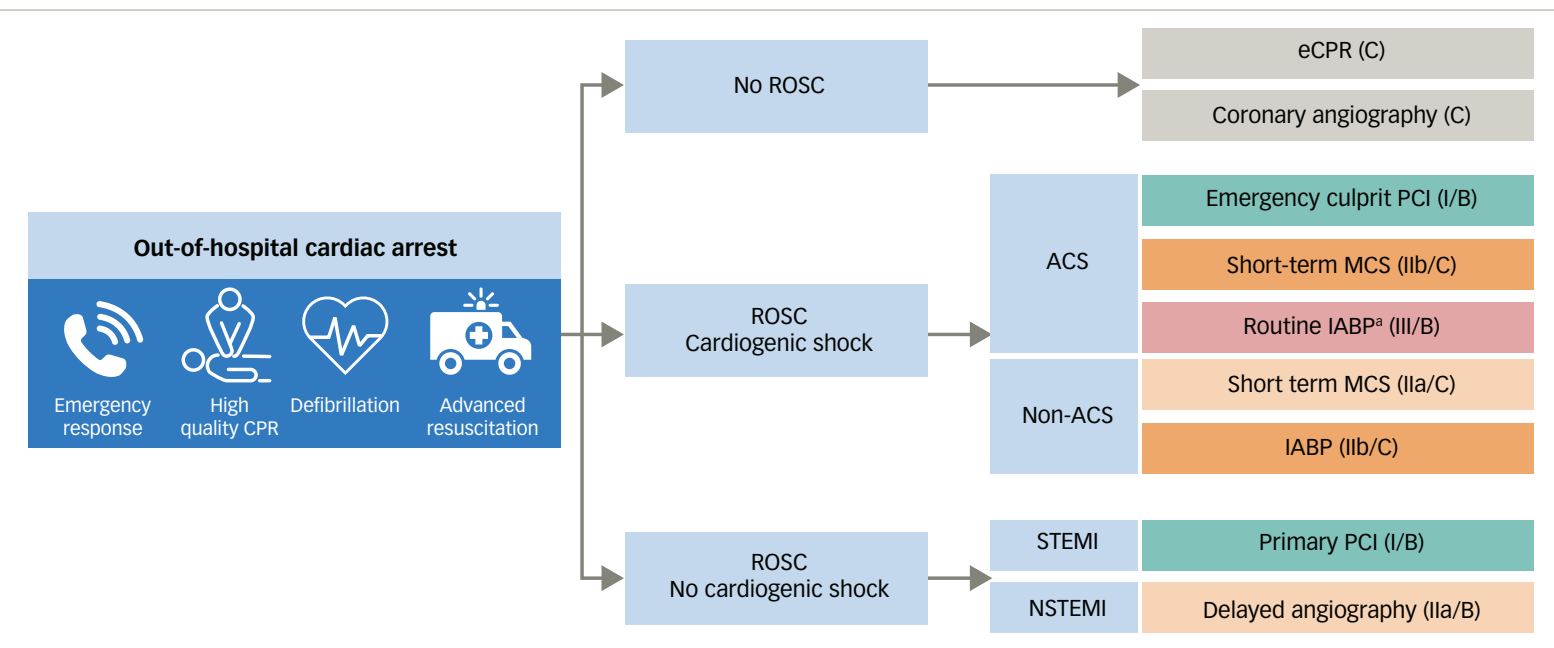

Class of recommendation I: is recommended; Ila: should be considered; IIb: may be considered; III: not recommended. Level of evidence A: multiple randomized clinical trials; $B$ : single randomized trial or large non-randomized studies; $C$ : expert consensus.

aAlthough routine IABP is not recommended, it should be considered for mechanical complications of ACS (IIa/C).

$A C S=$ acute coronary syndrome; $C P R=$ cardiopulmonary resuscitation; eCPR = extracorporeal cardiopulmonary resuscitation; IABP = intra-aortic balloon pump;

$M C S=$ mechanical circulatory support; NSTEMI = non-ST elevation myocardial infarction; $P C I=$ percutaneous coronary intervention; $R O S C=$ return of spontaneous circulation; STEMI = ST elevation myocardial infarction

Figure 2: Risks and benefits of catheter laboratory activation and an immediate angiography strategy after out-of-hospital cardiac arrest, particularly in those without cardiogenic shock or ST elevation

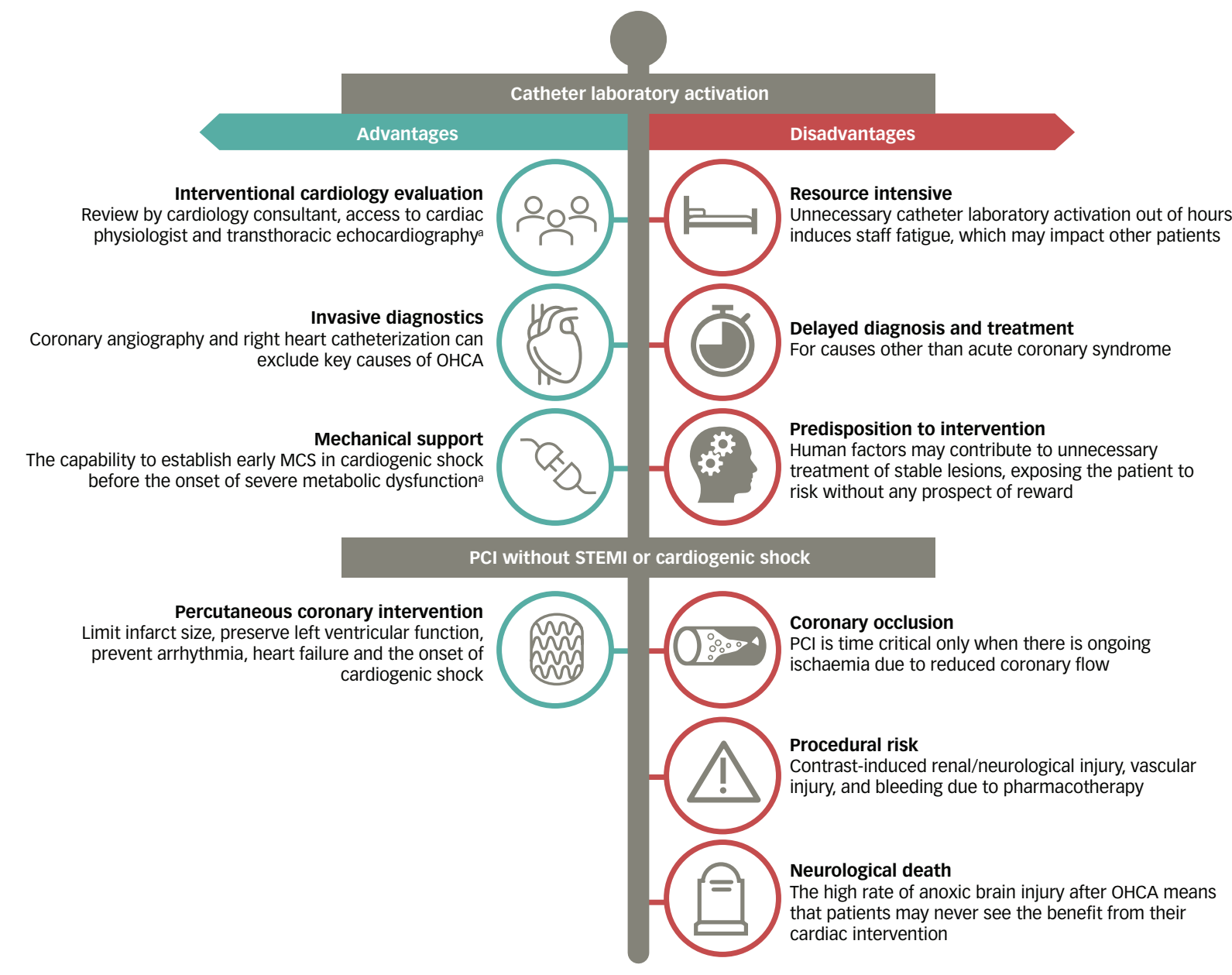


Table 1: Current national and international society guidelines on the timing of invasive coronary angiography after cardiac arrest ${ }^{5,33}$

\begin{tabular}{|l|l|l|}
\hline Society & Recommendation & \multicolumn{1}{|l}{ Grade } \\
\hline ESC $2020^{5}$ & $\begin{array}{l}\text { An immediate invasive strategy (<2 hours) is recommended in patients with at least one of: } \\
\text { - Haemodynamic instability or cardiogenic shock } \\
\text { - Life-threatening arrhythmias }\end{array}$ \\
\hline & $\begin{array}{l}\text { Delayed as opposed to immediate angiography should be considered among haemodynamically stable patients without } \\
\text { ST-elevation successfully resuscitated after out-of-hospital cardiac arrest }\end{array}$ & Ila/B \\
\hline SCAI 2020 & Deferring transport to CCL at initial encounter is recommended in OHCA patients with an initial non-shockable rhythm & Consensus \\
\hline & $\begin{array}{l}\text { Deferring invasive strategy at initial encounter is recommended in haemodynamically stable, comatose OHCA patients } \\
\text { without STEMI on post-ROSC ECG }\end{array}$ & Consensus \\
\hline
\end{tabular}

$C C L=$ cardiac catheter laboratory; ECG = electrocardiogram; ESC = European Society of Cardiology; OHCA = out-of-hospital cardiac arrest; ROSC = return of spontaneous circulation; SCAI = Society for Cardiovascular Angiography and Interventions; STEMI = ST elevation myocardial infarction.

studies, obstructive coronary disease (defined as $>50 \%$ stenosis in these studies) was identified in $89-96 \%$ of those with ST elevation and in $51-58 \%$ in those without. ${ }^{12,13}$ However, perhaps more relevant than the mere prevalence of coronary disease is thrombotic coronary occlusion. For those with stable coronary disease, a considered assessment of myocardial ischaemia and viability may be helpful before embarking on revascularization. ${ }^{14}$ In thrombotic occlusion, intervention is time critical. In these cases, resolving cardiac ischaemia may lead to preservation of left ventricular function, improvement in haemodynamics and the prevention of reinfarction and cardiac death. ${ }^{15}$ Acute coronary occlusion has been reported to be present in over $80 \%$ of those with ST elevation. For those who have an initial shockable rhythm (ventricular fibrillation [VF] or ventricular tachycardia [VT]) without ST elevation, acute occlusion is reported in $23 \% .^{16}$ The presence of refractory VF or VT (persistent after three shocks delivered by emergency medical services and administration of amiodarone) increases this further to $64 \% .^{17}$

In cardiogenic shock, the prompt revascularization or exclusion of a coronary culprit is also essential, given that acute coronary syndromes (ACS) are responsible for $81 \%$ of cases and cardiogenic shock carries a devastating short-term mortality. ${ }^{18}$

However, even in the presence of ST elevation, electrical instability or cardiogenic shock, another layer of complexity is introduced after OHCA. Although conscious patients have a favourable prognosis and their outcome is similar to the non-arrested ACS group, 12,19 after return of spontaneous circulation (ROSC) the majority will be comatose. Predicting the likelihood of neurological recovery in these patients is notoriously difficult.20,21 Therefore, while patients with ST elevation myocardial infarction (STEMI) or cardiogenic shock still undergo immediate angiography given its established benefits, ${ }^{18,22}$ the urgency with which patients without these features undergo coronary angiography is a matter of debate. Immediate catheter laboratory activation in these cases has the potential to expend significant resources, all within the initial 72 hours of uncertainty before any formal neuro-prognostication can be carried out. ${ }^{23}$

\section{Current guidelines and practice}

Wide variation exists in the management and outcomes of OHCA, including the use of coronary angiography after cardiac arrest, which reflects the lack of consensus and randomized data in previous years. In the UK national database of all catheter laboratory procedures, the rate of $\mathrm{PCl}$ undertaken in emergency ventilated patients as a proportion of total $\mathrm{PCl}$ within a centre (the majority of which are OHCA, and whose outcomes are censored from $\mathrm{PCl}$ operators' publicly available data) varies widely, from 0.0 to $4.7 \%$. This was independent of primary $\mathrm{PCl}$ volume or the provision of 24 -hour $\mathrm{PCl}$ at that centre. ${ }^{24}$ This variation has been similarly demonstrated in the USA and in France. ${ }^{25-27}$ This is despite contemporary guidance at the time of these studies recommending angiography within $<2$ hours following cardiac arrest, ${ }^{28,29}$ supported by multiple meta-analyses of observational data. ${ }^{30-32}$

The European Society of Cardiology now recommends that delayed angiography should be considered for haemodynamically stable patients after cardiac arrest without STEMI (Table 1).,53 This is consistent with the Society for Cardiovascular Angiography and Interventions consensus statement, which emphasizes that the OHCA group is a highly heterogeneous population and an individualized approach is required, ${ }^{33}$ with an assessment made of the factors that are likely to favour a good neurological recovery before proceeding to catheter laboratory activation. This change in recommendation reflects the publication of results from the first in a series of trials that have addressed the timing of angiography after cardiac arrest. ${ }^{34-36}$

\section{A new era of randomized controlled trials in cardiac arrest COACT}

The Coronary angiography after cardiac arrest trial (COACT; Netherlands Trial Register: NTR4973) was an investigator-initiated, multicentre trial in Holland that assessed the effect of an immediate versus a delayed angiography strategy on 90-day survival in patients who remained unconscious after OHCA (VF/NT arrest), but had no ST elevation on their electrocardiogram $(E C G){ }^{34,35}$ Angiography in the delayed arm was performed after neurological recovery, which was in general after discharge from the intensive care unit (ICU). Cardiogenic shock, refractory ventricular arrhythmia and a clear non-coronary cause were among the exclusion criteria. The trial was designed to detect a $40 \%$ difference in the primary outcome with $85 \%$ power, based on a predicted $45 \%$ survival in the immediate angiography arm and $32 \%$ in the delayed arm.

A total of 552 patients were randomized 1:1 from 2015 to 2018, with follow-up completed for $98 \%$. There was no significant difference in the primary outcome of survival at 90 days: $64.5 \%$ in the immediate group versus $67.2 \%$ in the delayed group (odds ratio $0.89,95 \%$ confidence interval $[\mathrm{Cl}], 0.62-1.27)$. This was much higher than anticipated in the power calculation for the trial, and double what was predicted for the delayed angiography arm, indicating that this is a lower-risk cohort than the investigators predicted. Neurological causes were responsible for the majority (64\%) of deaths. 
Despite the established reduction in mortality and vascular complications with radial access (and the exclusion of cardiogenic shock making the need for mechanical support devices and femoral access unlikely), ${ }^{37}$ radial access was used in only $41 \%$ of the immediate angiography group versus $73 \%$ in the delayed group. Furthermore, there was increased use of aspirin (87\% versus $76 \%$ ) and P2Y12 inhibitors (71\% versus 58\%) in the delayed angiography arm. Both these factors may have disadvantaged the immediate angiography group and potentially diluted any beneficial treatment effects.

\section{Commentary}

A proportion of the COACT patient population can be expected to have coronary occlusion despite the absence of ST elevation, and this group perhaps offers the greatest opportunity for benefit from $\mathrm{PCl}$. This was present in only $5 \%$ of those who underwent angiography, with a further $15 \%$ having an acutely unstable lesion, defined as a $\geq 70 \%$ stenosis with angiographic irregularity, dissection, haziness or thrombus. This is a small proportion of patients in whom an immediate PCl strategy could influence outcomes, let alone a $40 \%$ change in 90-day survival; hence, the trial is underpowered to assess benefit in this specific group.

Furthermore, the $\mathrm{PCI}$ rate in the immediate angiography arm was markedly higher than the rate of angiographic occlusion or unstable lesions (33\% versus $17 \%$ ). Defining an unstable lesion can be very difficult in non-STEMI. When cardiac magnetic resonance and late gadolinium enhancement are used to localise infarcted myocardium in the non-arrested population, an apparent angiographic culprit vesse matches the infarcted territory in less than half of patients. ${ }^{38}$ Nonetheless, this disparity suggests the revascularization of some stable lesions, which might expose the patient to the risks of $\mathrm{PCl}$ without any potential benefit. From the human factor perspective, we must resist the path of least resistance, which is for the interventional cardiologist to deliver a patient to intensive care 'fully revascularized' with no further intervention required, even if this is mutually beneficial for the intensivist, who then does not have to consider a return to the catheter laboratory as part of the patient's treatment course. We should work with our colleagues to emphasize that the presence of coronary disease does not imply a cause for OHCA, nor is it alone a clear mandate for coronary intervention. The act of performing coronary angiography in itself (whether immediately or delayed) must not predispose the patient to unnecessary intervention.

Targeted temperature management (TTM) is the only neuroprotective intervention currently recommended after $\mathrm{OHCA} .{ }^{23}$ The time to establish TTM (therapeutic hypothermia at $33-36^{\circ} \mathrm{C}$ at the time of these trials) was longer in the immediate angiography group (geometric mean of 6.5 [5.9-7.1] versus 5.5 [5.0-6.0] hours, $\mathrm{Cl} 95 \%$ )..$^{39}$ However, the large and well-designed TTM2 trial (with more participants than all previous randomized studies in therapeutic hypothermia combined) recently showed no difference in mortality or functional outcome between normothermia and hypothermia at $33^{\circ} \mathrm{C} .{ }^{40}$ It may be that hypothermia is simply a blunt tool for the avoidance of fever, which is known to be associated with poor outcomes. It therefore seems unlikely that the difference in time to TTM had a significant effect on outcomes in COACT.

\section{COACT summary}

In comatose patients after resuscitated VF or VT arrest and without ST elevation, a strategy of immediate versus delayed angiography did not show a significant difference in 90-day survival. A smaller effect size than $40 \%$ cannot be excluded, but any improvement in cardiac outcomes may also be concealed by the high proportion of deaths due to neurological injury. The lower-than-expected number of coronary occlusions may reflect patient selection, and limit extrapolation to an all-comers population.

\section{TOMAHAWK}

TOMAHAWK (Immediate unselected coronary angiography versus delayed triage in survivors of out-of-hospital cardiac arrest without ST-segment elevation; ClinicalTrials.gov identifier: NCT02750462) was an investigator-initiated, international, multicentre trial in Europe that assessed the effect of an immediate angiography versus a strategy of initial ICU evaluation on 30-day mortality in patients who had been resuscitated from OHCA and had no ST elevation. ${ }^{36}$ The delayed group could proceed to angiography after a minimum of 24 hours, or sooner if there was electrical instability, cardiogenic shock, new ST elevation, or troponin elevation to $>70$ times the upper limit of normal at 6 hours. Cardiogenic shock, electrical instability and a clear non-cardiac cause were among the exclusion criteria. The study was designed to reject the null hypothesis of no difference between groups with $80 \%$ power, based on previous observational data that predicted $34 \%$ mortality in those undergoing immediate angiography and $46 \%$ mortality with delayed angiography.

A total of 554 patients were randomized 1:1 from 2016 to 2019, with follow-up completed for $96 \%$. There was no significant difference in the primary outcome of 30 -day mortality: $54 \%$ in the immediate group versus $46 \%$ in the delayed group (hazard ratio 1.28 , 95\% Cl 1.00-1.63). The prespecified secondary endpoint of all-cause death or severe neurological deficit occurred in $64.3 \%$ of the immediate group versus $55.6 \%$ in the delayed group (relative risk 1.16, 95\% Cl 1.00-1.34), which should be viewed as hypothesis generating.

A culprit lesion was identified in $40 \%$ of patients in TOMAHAWK, with a similar rate of $\mathrm{PCl}$. However, the definition of a clinically relevant lesion warranting revascularization was left to the discretion of the operator. The rate of thrombotic coronary occlusion was not provided in this paper. Neurological injury was responsible for death in $40 \%$ of the patients.

\section{Commentary and comparisons with COACT}

It is worth highlighting some of the similarities and differences between COACT and TOMAHAWK (Figure 3). ${ }^{34-36}$ Due to difficulties in enrolment, the prematurely terminated PEARL (Early coronary angiography versus delayed coronary angiography; ClinicalTrials.gov identifier: NCT02387398) trial, which was conducted at the same time as these studies, has not been included for further comparison. ${ }^{41}$ The design of TOMAHAWK allowed for earlier coronary angiography in the delayed group, at a median of 47 hours (interquartile range [IQR] 26.1-116.6), versus 122 hours (IQR 52.0-197.3) in COACT where this was delayed until neurological recovery. A pragmatic approach allowed crossover from the delayed arm to angiography for set criteria suggestive of a coronary culprit. More extensive coronary disease was seen in TOMAHAWK, with $37 \%$ having three-vessel disease (versus 17\% in COACT), although the rates of coronary artery bypass graft, $\mathrm{PCl}$ and previous myocardial infarction were similar. Common findings were the low rates of radial angiography and the high rate of neurological death (also 40\%).

Do the reported numbers of acute coronary lesions in either of these trials represent the real-world prevalence of unstable coronary lesions after resuscitated and comatose VF/NT arrest? Observational series of patients without ST elevation would suggest identification of a culprit lesion in up to $33 \%$, with vessel occlusion in up to $23 \%$ of patients. ${ }^{12,15,42,43}$ How do we account for this discrepancy? After satisfying all inclusion and exclusion criteria (including the provision of informed consent), 
Figure 3: Comparison between COACT and TOMAHAWK trials ${ }^{34-36}$

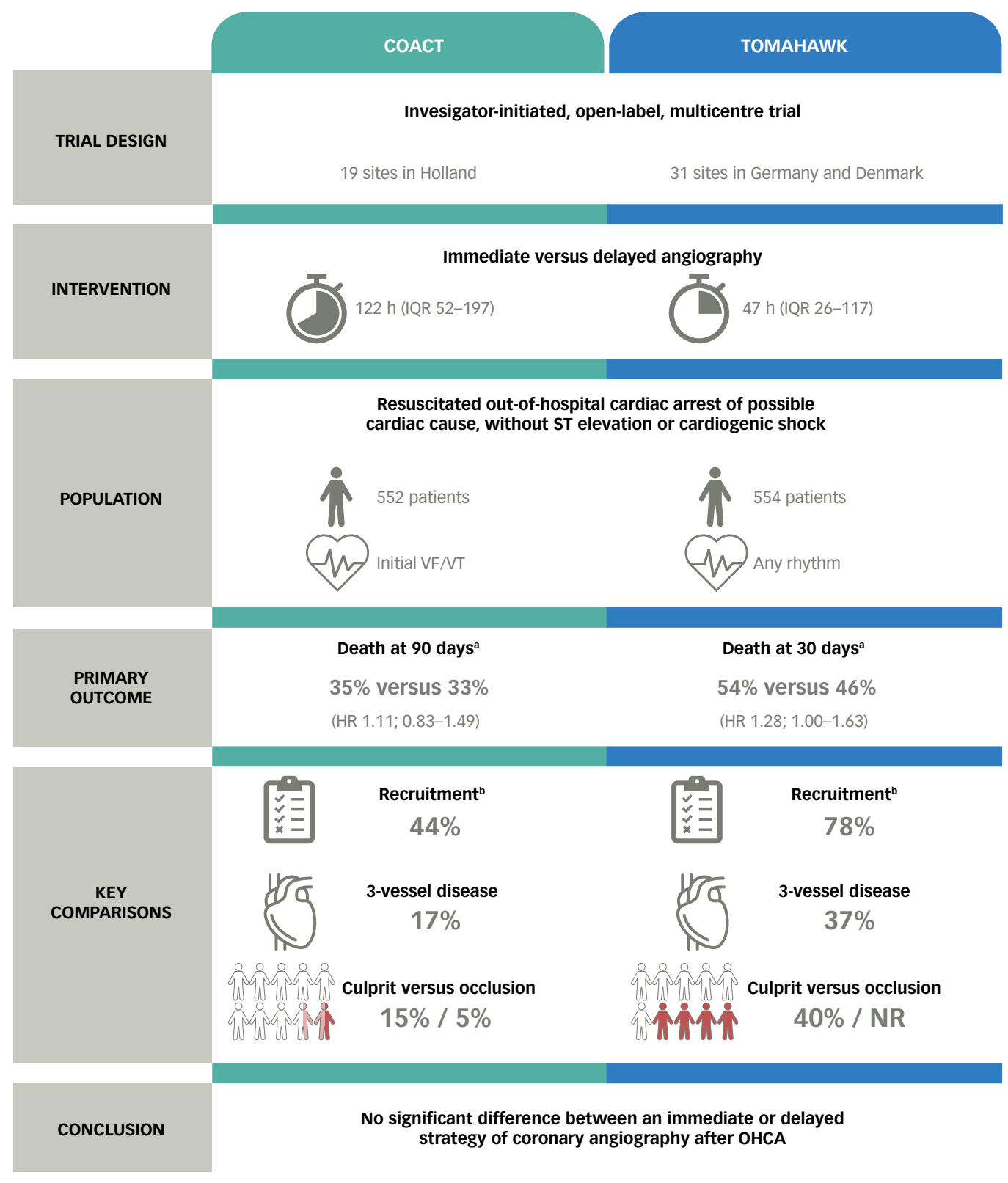

Time to delayed angiography specified as median

${ }^{a}$ The primary outcome in COACT was survival at 90 days, the hazard ratio for death is provided to allow comparison between trials. ${ }^{B}$ Complete screening logs were not maintained for either trial. The recruitment rate was calculated from the screening samples and based on the number of patients that were eligible for the trial after all inclusion (including informed consent for COACT) and exclusion criteria were applied.

$h=$ hours; $H R=$ hazard ratio; IQR = interquartile range; NR = not recorded; OHCA = out-of-hospital cardiac arrest; VF = ventricular fibrillation; $V T=$ ventricular tachycardia.

over half of the patients included in the COACT screening sample were still excluded for unspecified reasons. Without the benefit of a COACT registry to track the outcomes of these patients, and the TOMAHAWK registry being abandoned in the final protocol, we do not know the true prevalence of coronary occlusion in either population. We can speculate that clinicians would have been unwilling to randomize patients with a high probability of a coronary culprit lesion, such as a history of chest pain prior to cardiac arrest or a markedly ischaemic ECG. It has been the established standard of care for several years to offer immediate coronary angiography 'analogous to STEMI' in those with dynamic ST-T-wave changes even in the absence of ST elevation. ${ }^{28}$ The proportion of patients that were excluded in TOMAHAWK despite being otherwise suitable was lower (22\%), and it is possible that a more representative population was enrolled in this study.

\section{Treating the heart versus protecting the brain}

The COACT and TOMAHAWK trials confirm that many comatose patients after OHCA will ultimately go on to suffer neurological death. This poses a challenge when trying to ascertain the effects of an intervention such as immediate cardiac catheterization, as any longer-term benefits in left ventricular function, rehospitalization, reinfarction or cardiac mortality may be concealed by early neurological death. Even if these benefits do exist, it is clearly unhelpful to pursue them if the neurological outcome is futile.

When considering the role of the catheter laboratory in these patients, we should therefore focus on two priorities. First, how to select patients with a low risk of neurological death who are likely to see the benefits from any cardiac intervention. Second, how to select patients in whom 
Table 2: Risk scores for the prediction of poor neurological outcome (Cerebral Performance Category 3-5) after out-of-hospital cardiac arrest ${ }^{4-48}$

\begin{tabular}{|c|c|c|c|}
\hline Score & Components, outcome, specificity & Derivation cohort & AUC \\
\hline $\mathrm{OHCA}^{45}$ & $\begin{array}{l}\text { Creatinine, initial rhythm, no-flow time, low-flow time, lactate } \\
\text { Poor neurological outcome at hospital discharge } \\
\text { Moderate risk >17.4 (63\%), high risk } 32.5 \text { (77\%) }\end{array}$ & $\begin{array}{l}130 \text { patients from a single-centre } \\
\text { Paris registry }\end{array}$ & 0.82 \\
\hline $\mathrm{CAHP}^{44}$ & $\begin{array}{l}\text { Age, initial rhythm, location of arrest, low-flow time, no-flow time, pH, total adrenaline dose } \\
\text { Poor neurological outcome at hospital discharge } \\
\text { Moderate risk >150 (85\%), high risk >200 (98\%) }\end{array}$ & 819 patients from a Paris registry & 0.93 \\
\hline $\mathrm{TTM}^{46}$ & $\begin{array}{l}\text { Adrenaline use, age, GCS, initial rhythm, location of arrest, low-flow time, no-flow time, } \mathrm{PaCO}_{2^{\prime}} \mathrm{pH} \text {, } \\
\text { pupillary reflexes } \\
\text { Poor neurological outcome at } 6 \text { months } \\
\text { Moderate risk }>13(83 \%) \text {, high risk }>16 \text { (95\%) }\end{array}$ & $\begin{array}{l}933 \text { patients in Europe and Australia } \\
\text { in the TTM trial }{ }^{47}\end{array}$ & 0.84 \\
\hline $\operatorname{MIRACLE}_{2}^{48}$ & $\begin{array}{l}\text { Adrenaline use, age, initial rhythm, multiple intra-arrest rhythms, pH, pupillary reflexes, and } \\
\text { unwitnessed arrest } \\
\text { Poor neurological outcome at } 6 \text { months } \\
\text { Moderate risk }>2(57 \%) \text {, high risk }>4(91 \%)\end{array}$ & $\begin{array}{l}373 \text { patients from a single-centre } \\
\text { London registry }\end{array}$ & 0.90 \\
\hline
\end{tabular}

Specificity and AUC are specified for their derivation cohorts. If to be used in guiding treatment, high specificity is crucial i.e. treatment should not be withheld based on a score that has falsely predicted a poor neurological outcome.

$A \cup C=$ area under the curve; $C A H P=$ cardiac arrest hospital prognosis; $G C S=$ Glasgow coma score; $O H C A=$ out-of-hospital cardiac arrest; $P$ aCO ${ }_{2}=$ partial pressure of carbon dioxide; TTM = target temperature management.

the diagnosis or treatment of a coronary culprit should not be delayed. This is presumed in those with ST elevation, cardiogenic shock and electrical instability, ${ }^{5}$ but for patients with none of these features, can we identify those with a coronary occlusion who may benefit from immediate PCl?

Unfortunately, on the patient's arrival, the clinician is often faced with the need to answer these questions based on limited and imperfect information. A patient's history, comorbidities and wishes may be unknown. Therefore, decisions rest primarily on the characteristics of the resuscitation, the 12-lead ECG and results from point-of-care whole blood analysis.

\section{Neurological recovery}

The difficulty in predicting a patient's likely neurological outcome at admission has led to the development of several risk scores (Table 2). ${ }^{44-48}$ The Cardiac Arrest Hospital Prognosis (CAHP) score is applied on hospital admission, and the Out of Hospital Cardiac Arrest (OHCA) score and Target Temperature Management (TTM) score are used at the time of ICU admission. ${ }^{44-46}$ They all perform reasonably well within their corresponding derivation cohorts in predicting neurological outcomes. In a large registry, early invasive angiography was independently associated with survival only in those with a low $(<150)$ CAHP score (i.e. a presumed good outcome). ${ }^{27}$

The most recent of these is $\mathrm{MIRACLE}_{2}$, which requires prospective evaluation; however, it performed as well as or better than other scores in predicting poor neurological outcome within its validation cohort. Its key advantages are application on arrival to a heart attack centre, practicality of use with only seven variables (a score range of only 0-10) and avoiding unreliable measures of low-flow and no-flow times. ${ }^{48}$ Possible limitations include the generalizability of the score to an all-comers population, with both derivation and validation carried out in large tertiary centres, over half presenting with STEMI and 70\% with an initial shockable rhythm. As with all risk scores, we must be careful not to create a self-fulfilling prophecy where withholding care makes a poor outcome inevitable. The role of these risk scores in clinical practice, as well as what would be considered an 'acceptable' risk of poor neurological outcome with which to guide treatment decisions, have yet to be defined.

\section{Coronary culprits or coronary occlusions?}

If there is to be a benefit from immediate coronary angiography, it must lie in those with occlusion and/or ongoing ischaemia, rather than merely a 'culprit' lesion. How can we improve our chances of identifying these patients? COACT and TOMAHAWK have shown a stark difference in the rates of culprit lesions and vessel occlusion at angiography compared with previous observational data. The presence of an initial shockable rhythm has been shown to be a predictor of both survival and a coronary cause for cardiac arrest. ${ }^{49}$ However, if COACT is believed to be truly representative of an all-comers population, then VF/VT alone appears to be insufficient for predicting a culprit lesion or vessel occlusion.

The $\mathrm{ACS}^{2}$ score uses the presence of angina, congestive heart failure, a shockable arrest rhythm or the presence of ST elevation in two contiguous leads (2 points) to predict the presence of a culprit lesion. .0,51 $^{-1}$ Unfortunately, the absence of ST elevation reduces the area under the curve for this score to 0.74 . This study did not exclusively involve comatose patients, but we can infer that a collateral history revealing the presence of angina or heart failure symptoms prior to cardiac arrest increases the likelihood of a coronary culprit lesion.

At the simplest level, we have the post-resuscitation ECG. It is important to consider that exclusion of ST elevation leaves a wide spectrum of possible ECG findings, from dynamic and widespread ST changes to the completely normal ECG. In addition, the post-resuscitation ECG may be challenging to interpret, as it is often subject to metabolic derangement and ischaemia due to global low flow (as opposed to a coronary culprit) in the immediate post-ROSC phase. A retrospective study of 370 patients suggested that the false-positive rate for ECGs that meet STEMI criteria was significantly higher within the first 7 minutes after ROSC versus later ECGs (although the endpoint for this study was the subjective need for $\mathrm{PCl}$ rather than thrombolysis in myocardial infarction [TIMI] flow). ${ }^{52}$ Conversely, it has been suggested that typical patterns of cardiac ischaemia on the initial ECG (classical 
Figure 4: Management of the resuscitated out-of-hospital cardiac arrest patient ${ }^{33}$

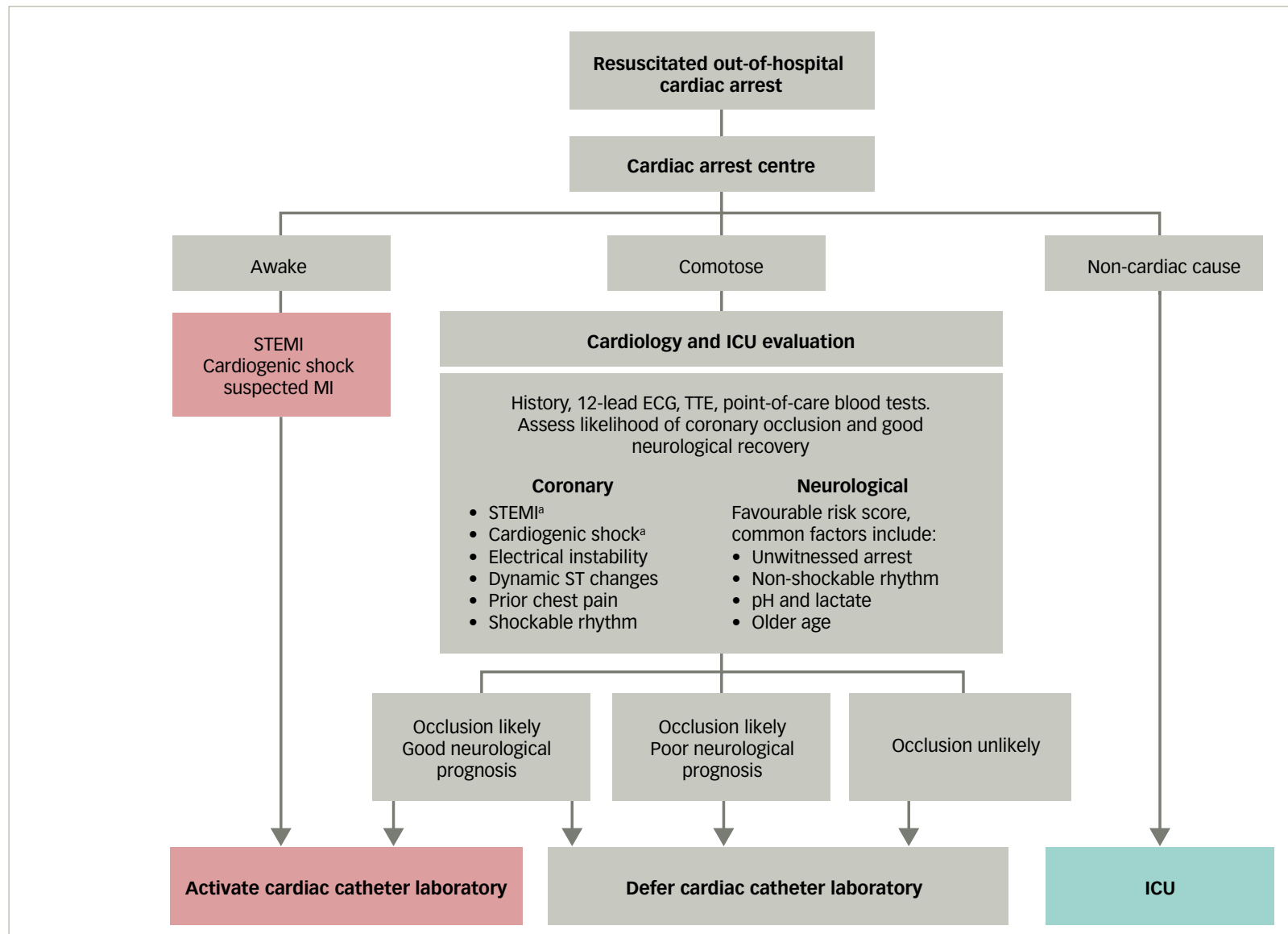

A likely coronary occlusion with ongoing ischaemia favours immediate catheter laboratory activation. A poor neurological prognosis should prompt consideration of a deferred catheter laboratory strategy. Adapted from Lotfi et al., 2020.33

${ }^{a}$ Given the established benefits of angiography and PCI in STEMI and cardiogenic shock, catheter laboratory activation should only be deferred if further treatment is considered unequivocally futile.

ECG = electrocardiogram; ICU = intensive care unit; $\mathrm{MI}=$ myocardial infarction; $P C l=$ percutaneous coronary intervention; STEMI = ST elevation myocardial infarction; TTE = transthoracic echocardiography.

STEMI; ST elevation in aVR with diffuse ST depression elsewhere; modified Sgarbossa criteria; posterior infarction) maintain their predictive accuracy for thrombotic occlusion, even in the presence of metabolic abnormalities. ${ }^{53}$

It is worth noting the prospectively defined observational NORCAST (Norwegian cardio-respiratory arrest study; ClinicalTrials.gov identifier: NCT01239420) study, which performed coronary angiography on 257 sequential resuscitated OHCA patients at a single centre, irrespective of ECG findings, provided there was no clear non-cardiac cause. ${ }^{43}$ In this study, an acute lesion was defined as the angiographic presence of thrombus or the ability to easily wire through the lesion. In 210 patients, acute TIMI 0-1 flow was identified in 11\% of patients even in the absence of any significant ST changes or bundle branch block on their first ECG after ROSC.43 This observational study remains significant even in the wake of COACT and TOMAHAWK, providing an insight into the true prevalence of acute coronary occlusion after OHCA and demonstrating that the initial 12-lead ECG alone appears insufficient for predicting coronary anatomy.

\section{Evaluation and management of the out-of-hospital arrest patient}

In the absence of definitive evidence and faced with the diagnostic and prognostic uncertainty of the post-cardiac arrest patient, clinicians making decisions based on anecdotal experience can lead to either extremes of unfounded nihilism or speculative optimism and potential for waste of limited resources. Immediate activation of the catheter laboratory affects the provision of services for other patients, and out-of-hours work induces team fatigue and a potential loss of workforce for the following day. These effects will be most marked in small and low-volume centres. While observational studies have previously suggested a benefit for early angiography, we now have randomized evidence to guide decision making. Although there are limitations to both COACT and TOMAHAWK, the message from both is consistent: in the absence of ST elevation or cardiogenic shock, a routine strategy of immediate coronary angiography has no benefit.

Admission to a cardiac arrest centre with access to all diagnostic and therapeutic services on site, as well as high-volume provider experience in the management of $\mathrm{OHCA}$, is recommended, ${ }^{54}$ and allows immediate multidisciplinary evaluation of these patients (Figure 4). ${ }^{33}$ ST elevation, cardiogenic shock and/or suspected myocardial infarction in the awake patient should proceed directly to immediate catheter laboratory activation. This should also be the case in the comatose patient with ST elevation or cardiogenic shock unless they are clearly moribund with multiple adverse features. Given the difficulties in early neuro-prognostication, the threshold for not proceeding to the catheter laboratory in these cases should be set high. 
Table 3: Completed and ongoing trials in out-of-hospital cardiac arrest. A clear non-cardiac cause or ST elevation are exclusion criteria for all these trials ${ }^{33,36,625,55.59}$

\begin{tabular}{|c|c|c|c|c|c|}
\hline Title & Date & $\mathrm{n}$ & Inclusion/Key exclusion & Treatment arms & Primary outcome \\
\hline \multicolumn{6}{|l|}{ Completed } \\
\hline $\begin{array}{l}\text { Coronary angiography after cardiac arrest } \\
(\text { COACT, NTR4973) })^{34}\end{array}$ & 2020 & 552 & $\begin{array}{l}\text { Resuscitated VFNT OHCA with } \\
\text { GCS }<8 \\
\text { Cardiogenic shock, refractory } \\
\text { ventricular arrhythmia }\end{array}$ & $\begin{array}{l}\text { Immediate versus } \\
\text { delayed (neurological } \\
\text { recovery) angiography }\end{array}$ & $\begin{array}{l}\text { 90-day survival (OR 0.89, 95\% } \\
\mathrm{Cl} 0.62-1.27)\end{array}$ \\
\hline $\begin{array}{l}\text { Randomized pilot clinical trial of early } \\
\text { coronary angiography versus no early } \\
\text { coronary angiography after cardiac arrest } \\
\text { without ST-segment elevation (PEARL, } \\
\text { NCT02387398) }{ }^{42}\end{array}$ & 2020 & $99 / 226$ & Resuscitated OHCA and comatose & $\begin{array}{l}\text { Immediate versus } \\
\text { delayed ( }>6 \text { hours) } \\
\text { angiography }\end{array}$ & $\begin{array}{l}\text { Composite of efficacy and } \\
\text { safety }(55.1 \% \text { versus } 46.0 \% \text {; } \\
p=0.64)\end{array}$ \\
\hline $\begin{array}{l}\text { Immediate unselected coronary angiography } \\
\text { versus delayed triage in survivors of out-of- } \\
\text { hospital cardiac arrest without ST-segment } \\
\text { elevation (TOMAHAWK, NCT02750462) }{ }^{36}\end{array}$ & 2021 & 554 & $\begin{array}{l}\text { Resuscitated OHCA } \\
\text { Cardiogenic shock, electrical } \\
\text { instability }\end{array}$ & $\begin{array}{l}\text { Immediate versus } \\
\text { selective delayed } \\
\text { (>24 hours) angiography }\end{array}$ & $\begin{array}{l}\text { 30-day mortality (HR 1.28, } \\
95 \% \mathrm{Cl} 1.00-1.63 \text { ) }\end{array}$ \\
\hline \multicolumn{6}{|l|}{ In progress } \\
\hline $\begin{array}{l}\text { Emergency versus delayed coronary } \\
\text { angiogram in survivors of out-of-hospital } \\
\text { cardiac arrest (EMERGE, NCT02876458) }\end{array}$ & 2020 & 970 & Resuscitated OHCA & $\begin{array}{l}\text { Immediate versus } \\
\text { delayed (48-96 hours) } \\
\text { angiography }\end{array}$ & $\begin{array}{l}\text { 180-day survival with good } \\
\text { neurological outcome (CPC } \\
1 \text { or } 2 \text { ) }\end{array}$ \\
\hline $\begin{array}{l}\text { Coronariography in out of hospital cardiac } \\
\text { arrest (COUPE, NCT02641626) }\end{array}$ & 2021 & $72 / 166$ & $\begin{array}{l}\text { Resuscitated OHCA with GCS } \leq 8 \\
\text { after CT head and TTE } \\
\text { Cardiogenic shock, ROSC } \\
>60 \text { minutes }\end{array}$ & $\begin{array}{l}\text { Immediate versus } \\
\text { delayed (after extubation) } \\
\text { angiography }\end{array}$ & $\begin{array}{l}\text { 30-day and 6-month survival } \\
\text { with good neurological } \\
\text { outcome (CPC } 1 \text { or 2), MACE } \\
\text { (death, MI, bleeding or } \\
\text { ventricular arrhythmia) }\end{array}$ \\
\hline $\begin{array}{l}\text { A randomised trial of expedited transfer to } \\
\text { a cardiac arrest centre for non-ST elevation } \\
\text { out-of-hospital cardiac arrest (ARREST, } \\
\text { ISRCTN96585404) } \text { I7 }^{57}\end{array}$ & Est. 2022 & 860 & Resuscitated OHCA & $\begin{array}{l}\text { Expedited transfer to } \\
\text { cardiac arrest centre } \\
\text { versus standard of care }\end{array}$ & 30-day all-cause mortality \\
\hline $\begin{array}{l}\text { Direct or subacute coronary angiography in } \\
\text { out-of-hospital cardiac arrest (DISCO-MAIN, } \\
\text { NCT02309151) }\end{array}$ & Est. 2024 & 1,006 & $\begin{array}{l}\text { Resuscitated witnessed OHCA with } \\
\mathrm{GCS} \leq 8\end{array}$ & $\begin{array}{l}\text { Immediate versus } \\
\text { delayed (>3 days) } \\
\text { angiography }\end{array}$ & 30-day survival \\
\hline $\begin{array}{l}\text { Direct or subacute coronary angiography } \\
\text { in patients with out of hospital cardiac } \\
\text { arrest without coma (DISCO-no-COMA., } \\
\text { NCT04876222) }\end{array}$ & Est. 2026 & 1,200 & $\begin{array}{l}\text { Resuscitated witnessed OHCA with } \\
\text { GCS }>8\end{array}$ & $\begin{array}{l}\text { Immediate versus } \\
\text { delayed (12-24 hours) } \\
\text { angiography }\end{array}$ & $\begin{array}{l}\text { 30-day MACE (death, } \\
\text { cardiogenic shock or } \\
\text { recurrent cardiac arrest) }\end{array}$ \\
\hline
\end{tabular}

$\mathrm{Cl}=$ confidence interval; $\mathrm{CPC}=$ cerebral performance categories; $\mathrm{CT}=$ computed tomography; Est. = estimated; GCS = Glasgow coma Score; HR = hazard ratio;

$M A C E=$ major adverse cardiovascular events; $M I=$ myocardial infarction; OHCA = out-of-hospital cardiac arrest; OR = odds ratio; ROSC = return of spontaneous circulation;

TTE = transthoracic echocardiogram; Unk = unknown; VF = ventricular fibrillation; $V T=$ ventricular tachycardia.

In the comatose patient, an assessment of the likely neurological outcome, as well as the likelihood of ongoing coronary occlusion, should be made. For the vast majority of patients, an initial admission to the ICU for stabilization and diagnostic evaluation (including serial ECGS) is appropriate. Subsequent development of ST elevation, widespread ST changes, haemodynamic or electrical instability would then favour immediate ( $<2$ hours) catheter laboratory activation, which is largely in line with current guidance. ${ }^{5}$ In the absence of these features, a delayed angiography strategy until neurological prognostication can be carried out and alternative diagnoses excluded seems reasonable (Figure 4). ${ }^{33}$

\section{Future directions}

The DISCO study (Direct or subacute coronary angiography in out-of-hospital cardiac arrest; ClinicalTrials.gov identifier: NCT02309151) is recruiting over 1,000 comatose patients in Sweden following resuscitated cardiac arrest without ST elevation or cardiogenic shock, and randomizing them to immediate versus delayed (12-24 hours) angiography. ${ }^{55}$ This has expanded in 2021 to all tertiary centres in Denmark who will also recruit non-comatose patients into the separate, similarly sized DISCO-no-COMA study (Direct or subacute coronary angiography in patients with out of hospital cardiac arrest without coma; ClinicalTrials.gov identifier: NCT04876222). ${ }^{56}$ All patients after a resuscitated cardiac arrest who do not proceed to immediate coronary angiography will therefore be eligible for enrolment into a trial, providing the largest and most comprehensive study in this population to date (Table 3). . $^{34,3,42,55-59}$

The ARREST trial (A randomised trial of expedited transfer to a cardiac arrest centre for non-ST elevation out-of-hospital cardiac arrest; ClinicalTrials.gov identifier: NCT03872960) will test whether changes at a network level can potentially form an earlier link in the chain of survival, by testing expedited transfer to the cardiac catheter laboratory of a heart attack centre versus standard care. ${ }^{57}$ Although there remains uncertainty about which components of post-cardiac arrest care improve outcomes, the authors hypothesize that treatment within a tertiary centre with provider experience and the full range of diagnostic and interventional services available will reduce overall mortality.

The next 5 years promise a wealth of data and further answers to help deliver the optimal treatment, and to definitively establish the role of the catheter laboratory after resuscitated OHCA. • 
1. Kiguchi T, Okubo M, Nishiyama C, et al. Out-of-hospital cardiac arrest across the world: first report from the International Liaison Committee on Resuscitation (LCOR). Resuscitation. 2020;152:39-49.

2. Ong MEH, Shin SD, Souza NNA, et al. Outcomes for out-of-hospital cardiac arrests across 7 countries in Asia: the Pan Asian Resuscitation Outcomes Study (PAROS). Resuscitation. 2015;96:100-8.

3. Gräsner JT, Herlitz J, Tjelmeland IBM, et al. European Resuscitation Council Guidelines 2021: epidemiology of cardiac arrest in Europe. Resuscitation. 2021;161:61-79.

4. Ibanez B, James S, Agewall S, et al. 2017 ESC Guidelines for the management of acute myocardial infarction in patients presenting with ST-segment elevation. The task force for the management of acute myocardial infarction in patients presenting with ST-segment elevation of the European Society of Cardiology (ESC). Eur Heart J. 2018;39:119-77.

5. Collet J-P, Thiele H, Barbato E, et al. 2020 ESC Guidelines for the management of acute coronary syndromes in patients presenting without persistent ST-segment elevation. The task presenting without persistent ST-segment elevation. The task
force for the management of acute coronary syndromes in patients presenting without persistent ST-segment elevation of the European Society of Cardiology (ESC). Eur Heart J. 2021;42:1289-367.

6. Ponikowski P, Voors AA, Anker SD, et al. 2016 ESC Guidelines for the diagnosis and treatment of acute and chronic heart failure. The task force for the diagnosis and treatment of acute and chronic heart failure of the European Society of Cardiology (ESC) developed with the special contribution of the Heart Failure Association (HFA) of the ESC. Eur Heart I. 2016;37:2129-200.

7. Richardson AC, Tonna JE, Nanjayya V, et al. Extracorporeal cardiopulmonary resuscitation in adults. Interim guideline consensus statement from the Extracorporeal Life Support Organization. ASAIO J. 2021;67:221-8.

8. Merchant RM, Topjian AA, Panchal AR, et al. Part 1: executive summary: 2020 American Heart Association guidelines for cardiopulmonary resuscitation and emergency cardiovascular care. Circulation. 2020;142:S337-57.

9. Engdahl J, Holmberg M, Karlson BW, et al. The epidemiology of out-of-hospital 'sudden' cardiac arrest. Resuscitation. 2002;52:235-45

10. Storm C, Krannich A, Schachtner T, et al. Impact of acute kidney injury on neurological outcome and long-term survival after cardiac arrest - a 10 year observational follow up. J Crit Care. 2018;47:254-9

11. Park JS, You Y, Min JH, et al. Study on the timing of severe blood-brain barrier disruption using cerebrospinal fluid-serum albumin quotient in post cardiac arrest patients treated with targeted temperature management. Resuscitation. 2019:135:118-23.

12. Dumas F, Cariou A, Manzo-Silberman S, et al. Immediate percutaneous coronary intervention is associated with bette survival after out-of-hospital cardiac arrest. Circ Cardiovasc Interv 2010:3200-7.

13. Garcia-Tejada J, Jurado-Román A, Rodríguez J, et al. Post-resuscitation electrocardiograms, acute coronary finding and in-hospital prognosis of survivors of out-of-hospital cardiac arrest. Resuscitation. 2014;85:1245-50.

14. Ryan M, Morgan $\mathrm{H}$, Chiribiri A, et al. Myocardial viability testing: all STICHed up, or about to be REVIVED? Eur Heart J. 2021; doi: 10.1093/eurheartj/ehab729.

15. Huynh T, Perron S, O'Loughlin J, et al. Comparison of primary percutaneous coronary intervention and fibrinolytic therapy in ST-segment-elevation myocardial infarction. Circulation. 2009;119:3101-9.

16. Kern KB, Lotun $\mathrm{K}$, Patel $\mathrm{N}$, et al. Outcomes of comatose cardiac arrest survivors with and without ST-segment elevation myocardial infarction: importance of coronary angiography. JACC Cardiovasc Interv. 2015;8:1031-40.

17. Yannopoulos D, Bartos JA, Raveendran G, et al. Coronary artery disease in patients with out-of-hospital refractory ventricular fibrillation cardiac arrest. J Am Coll Cardiol. 2017;70:1109-17.

18. Harjola V-P, Lassus J, Sionis A, et al. Clinical picture and risk prediction of short-term mortality in cardiogenic shock Eur J Heart Fail. 2015;17:501-9.

19. Hosmane VR, Mustafa NG, Reddy VK, et al. Survival and neurologic recovery in patients with ST-segment elevation yocardial infarction resuscitated from cardiac arrest. I Am Coll Cardiol. 2009:53:409-15.

20. Sandroni C, D'Arrigo S, Nolan JP. Prognostication after cardiac arrest. Crit Care. 2018;22:150

21. Radsel P, Knafelj R, Kocjancic S, Noc M. Angiographic characteristics of coronary disease and postresuscitation electrocardiograms in patients with aborted cardiac arrest outside a hospital. Am J Cardiol. 2011;108:634-8.

22. Hochman JS, Sleeper LA, Webb JG, et al. Early revascularization in acute myocardial infarction complicated by cardiogenic shock. N Engl J Med. 2008;341:625-34.

23. Nolan JP, Sandroni C, Böttiger BW, et al. European Resuscitation Council and European Society of Intensive Care Medicine guidelines 2021: post-resuscitation care. Intensive Care Med. 2021;47:369-421.

24. Rawlins J, Ludman PF, O'Neil D, et al. Variation in emergency percutaneous coronary intervention in ventilated patients in the UK: insights from a national database. Cardiovasc Revasc Med. 2017:18:250-4

25. Balian S, Buckler DG, Blewer AL, et al. Variability in survival and post-cardiac arrest care following successful resuscitation from out-of-hospital cardiac arrest Resuscitation. 2019;137:78-86

26. Nathan AS, Shah RM, Khatana SA, et al. Effect of public reporting on the utilization of coronary angiography after out-of-hospital cardiac arrest. Circ Cardiovasc Interv. 2019;12:e007564

27. Bougouin W, Dumas F, Karam N, et al. Should we perform an immediate coronary angiogram in all patients after cardiac arrest? Insights from a large French registry. JACC Cardiovase Interv. 2018;11:249-56.

28. Roffi M, Patrono C, Collet J-P, et al. 2015 ESC Guidelines for the management of acute coronary syndromes in patients renting without persistent ST pere for

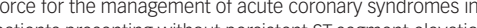
of the European Society of Cardiology (ESC). Eur Heart I. 2016;37:267-315

29. Noc M, Fajadet J, Lassen JF, et al. Invasive coronary treatment strategies for out-of-hospital cardiac arrest: a consensus statement from the European Association for Percutaneous Cardiovascular Interventions (EAPCI)/stent for life (SFL) groups Eurolntervention. 2014;10:31-7.

30. Khan MS, Shah SMM, Mubashir A, et al. Early coronary angiography in patients resuscitated from out of hospita cardiac arrest without ST-segment elevation: a systematic review and meta-analysis. Resuscitation. 2017:121:127-34.

31. Millin MG, Comer AC, Nable JV, et al. Patients without ST elevation after return of spontaneous circulation may benefit from emergent percutaneous intervention: a systematic review and meta-analysis. Resuscitation. 2016:108:54-60.

32. Khera $\mathrm{R}$, CarllLee $\mathrm{S}$, Blevins $\mathrm{A}$, et al. Early coronary angiography and survival after out-of-hospital cardiac arrest: a systematic review and meta-analysis. Open Heart. 2018;5:e000809.

33. Lotfi A, Klein LW, Hira RS, et al. SCAl expert consensus statement on out of hospital cardiac arrest. Catheter Cardiovasc Interv. 2020;96:844-61.

34. Lemkes JS, Janssens GN, van der Hoeven NW, et al. Coronary angiography after cardiac arrest without ST-segment elevation. N Engl J Med. 2019;380:1397-407.

35. Lemkes JS, Janssens GN, van der Hoeven NW, et al. Coronary angiography after cardiac arrest without ST segment elevation: one-year outcomes of the COACT randomized clinical trial. JAMA Cardiol. 2020;5:1358-65.

36. Desch S, Freund A, Akin I, et al. Angiography after out-of-hospital cardiac arrest without ST-segment elevation. N Eng/ / Med. 2021. Available at: doi:10.1056/NEJMoa2101909 (accessed 25 November 2021).

37. Chiarito M, Cao D Nicolas It et al. Radial versus femoral access for coronary interventions: an updated systematic review and meta-analysis of randomized trials. Catheter Cardiovasc Inter 2021;97:1387-96

38. Heitner JF, Senthilkumar A, Harrison JK, et al. Identifying the infarct-related artery in patients with non-ST-segmentelevation myocardial infarction. Circ Cardiovasc Interv. 2019;12:e007305.

39. Nolan JP, Soar J, Cariou A, et al. European Resuscitation Council and European Society of Intensive Care Medicine 2015 guidelines for post-resuscitation care. Intensive Care Med. 2015:41:2039-56.

40. Dankiewicz J Cronberg T, Lilia G, et al. Hypothermia versus normothermia after out-of-hospital cardiac arrest. N Engl Med. 2021;384:2283-94.

41. Kern KB, Radsel P. Jentzer JC, et al. Randomized pilot clinical trial of early coronary angiography versus no early coronary angiography after cardiac arrest without ST-segment elevation. Circulation. 2020;142:2002-12.

42. Spaulding CM, Joly L-M, Rosenberg A, et al. Immediate coronary angiography in survivors of out-of-hospital cardiac arrest. N Eng/ J Med. 2009;336:1629-33.

43. Stær-Jensen H, Nakstad ER, Fossum E, et al. Post-resuscitation ECG for selection of patients for immediate coronary angiography in out-of-hospital cardiac arrest. Circ Cardiovasc Interv. 2015;8:e002784

44. Maupain C, Bougouin W, Lamhaut L, et al. The CAHP (Cardiac Arrest Hospital Prognosis) score: a tool for risk stratification after out-of-hospital cardiac arrest. Eur Heart J. 2016;37:3222-8.

. Adrie C, Cariou A, Mourvillier B, et al. Predicting survival with good neurological recovery at hospital admission after successful resuscitation of out-of-hospital cardiac arrest: the successful resuscitation of out-of-hospita

46. Martinell L, Nielsen N, Herlitz J, et al. Early predictors of poor outcome after out-of-hospital cardiac arrest. Crit Care. 2017;21:96

47. Nielsen N, Wetterslev J, Cronberg T, et al. Targeted temperature management at $33^{\circ} \mathrm{C}$ versus $36^{\circ} \mathrm{C}$ after cardiac arrest. N Eng/ J Med. 2013;369:2197-206.

48. Pareek N, Kordis P, Beckley-Hoelscher N, et al. A practical risk score for early prediction of neurological outcome after out-of-hospital cardiac arrest: MIRACLE2. Eur Heart 2020:41:4508-17.

49. Sasson C, Rogers MAM, Dahl J, Kellermann AL. Predictors of survival from out-of-hospital cardiac arrest. Circ Cardiovasc Qual Outcomes. 2010:3:63-81.

50. Waldo SW, Chang L, Strom JB, et al. Predicting the presence of an acute coronary lesion among patients resuscitated from cardiac arrest. Circ Cardiovasc Interv. 2015;8:e0021

51. Kelham M, Jones TA, Rathod K, et al. 151 validation of the ACS2 score for predicting the presence of an acute coronary lesion in patients following out of hospital cardiac arrest. Heart. 2019;105(Suppl. 6):A126

52. Baldi E, Schnaubelt S, Caputo ML, et al. Association of timing of electrocardiogram acquisition after return of spontaneous circulation with coronary angiography findings in patients with out-of-hospital cardiac arrest. JAMA Netw Open. 2021:4:e2032875.

53. Sharma A, Miranda DF, Rodin $\mathrm{H}$, et al. Do not disregard the initial 12 lead ECG after out-of-hospital cardiac arrest: it predicts angiographic culprit despite metabolic abnormalities. Resusc Plus. 2020:4:100032.

54. Semeraro F Greif R, Böttiger BW, et al. European Resuscitation Council Guidelines 2021: systems saving lives. Resuscitation. 2021;161:80-97

55. Lagedal R, Elfwén L, James S, et al. Design of DISCO - direct or subacute coronary angiography in out-of-hospital cardiac arrest study. Am Heart J. 2018;197:53-61.

56. ClinicalTrials.gov. Direct or subacute coronary angiography in patients with out of hospital cardiac arrest without coma. (DISCO-noCOMA). ClinicalTrials. gov Identifier: NCT04876222. Available at: https://clinicaltrials.gov/ct2/show/NCT04876222 (accessed 25 November 2021).

57. Patterson T, Perkins A, Perkins GD, et al. Rationale and design of: a randomized trial of expedited transfer to a cardiac arrest center for non-ST elevation out-of-hospital cardiac arrest: the ARREST randomized controlled trial. Am Hearts. 2018;204:92-101.

58. ClinicalTrials.gov. Emergency versus delayed coronary angiogram in survivors of out-of-hospital cardiac arres (EMERGE). ClinicalTrials.gov Identifier: NCT02876458. Available at: https://clinicaltrials.gov/ct2/show/NCT02876458 (accessed 25 November 2021).

59. ClinicalTrials.gov. Coronariography in out of hospital cardiac arrest (COUPE). ClinicalTrials.gov Identifier: NCT02641626. Available at: Www.clinicaltrials.gov/ct2/show/NCT02641626 (accessed 25 November 2021). 